\title{
Neutralization of SARS-CoV-2 lineage B.1.1.7 pseudovirus by BNT162b2 vaccine-elicited human sera
}

\author{
Alexander Muik', Ann-Kathrin Wallisch', Bianca Sänger'1, Kena A. Swanson², Julia Mühl', Wei Chen², Hui Cai², \\ Daniel Maurus' ${ }^{1}$, Ritu Sarkar ${ }^{2}$, Özlem Türeci' ${ }^{1}$, Philip R. Dormitzer² ${ }^{2}$ Uğur Şahin ${ }^{1,3 *}$ \\ 1BioNTech, An der Goldgrube 12, 55131 Mainz, Germany. 2Pfizer, 401 N Middletown Rd., Pearl River, NY 10960, USA. ${ }^{3 T R O N ~ g G m b H ~-~ T r a n s l a t i o n a l ~ O n c o l o g y ~ a t ~ t h e ~}$ \\ University Medical Center of the Johannes Gutenberg, University Freiligrathstraße 12, 55131 Mainz, Germany. \\ ${ }^{*}$ Corresponding author. Email: ugur.sahin@biontech.de
}

Recently, a new SARS-CoV-2 lineage called B.1.1.7 (variant of concern: VOC 202012/01) emerged in the United Kingdom that was reported to spread more efficiently and faster than other strains. This variant has an unusually large number of mutations with 10 amino acid changes in the spike protein, raising concerns that its recognition by neutralizing antibodies may be affected. Here, we tested SARS-CoV-2-S pseudoviruses bearing either the Wuhan reference strain or the B.1.1.7 lineage spike protein with sera of 40 participants who were vaccinated in a previously reported trial with the mRNA-based COVID-19 vaccine BNT162b2. The immune sera had slightly reduced but overall largely preserved neutralizing titers against the B.1.1.7 lineage pseudovirus. These data indicate that the B.1.1.7 lineage will not escape BNT162b2mediated protection.

In a phase 3 trial conducted in the United States, Argentina, Brazil, South Africa, Germany, and Turkey, the BioNTechPfizer mRNA vaccine BNT162b2 was $95 \%$ effective in preventing COVID-19 through the data cut-off date of November 14, 2020 (1). The SARS-CoV-2 lineage B.1.1.7 was discovered to have emerged in the United Kingdom in September 2020 (2), and it subsequently increased in prevalence, showed enhanced transmissibility, and spread to other countries and continents (3). B.1.1.7 has a series of mutations in its spike (S) protein: $\Delta \mathrm{H} 69 / \mathrm{V} 70, \Delta \mathrm{Y} 144$, N501Y, A570D, D614G, P681H, T716I, S982A, and D1118H. One of these mutations, N501Y, was of particular concern because it is located in the receptor binding site. The spike with this mutation binds more tightly to its cellular receptor, ACE-2 (4); and virus with this mutation has an increased host range that includes mice (5). BNT162b2-immune sera neutralized SARS-CoV-2 (USA/WA1/2020 background strain) with an introduced N501Y mutation as efficiently as SARS-CoV-2 without the mutation (6). Further, 19 pseudoviruses, each bearing a SARS-CoV-2 S with a different mutation found in circulating virus strains, were also neutralized as efficiently as non-mutant SARS-CoV-2 S bearing pseudoviruses by BNT162b2-immune sera (7). The question remained whether a virus with the full set of mutations in the lineage B.1.1.7 spike each of which may potentially interfere with antibody binding would be neutralized efficiently by BNT162b2-immune sera.

To answer this question, we generated VSV-SARS-CoV-2$\mathrm{S}$ pseudoviruses bearing the Wuhan reference strain or the lineage B.1.1.7 spike protein (fig. S1). An unbiased set of sera of 40 participants in the previously reported German phase 1/2 trial (7), drawn from 26 younger (23-55 years) and 14 older adults (57-73 years) at 7 or 21 days after the booster immunization with $30 \mu \mathrm{g}$ BNT162b2 (fig. S2), were tested for neutralization of SARS-CoV-2 Wuhan and lineage B.1.1.7 spike-pseudotyped VSV by a $50 \%$ neutralization assay $\left(\mathrm{pVNT}_{50}\right)$. The $50 \%$ neutralization geometric mean titer (GMT) of the sera against the SARS-CoV-2 lineage B.1.1.7 spike-pseudotyped VSV for the younger adult group and the full analysis set were slightly, statistically significantly reduced compared to the GMTs against the Wuhan reference spike-pseudotyped VSV (Fig. 1 and table S1). GMTs were not significantly different for the older adult group. The calculated geometric mean ratio with $95 \%$ confidence interval of the B.1.1.7 pseudotype and the Wuhan pseudotype GMTs was $0.78[0.68 ; 0.89]$ for the younger and $0.83[0.65 ; 1.1]$ for the older adults $(0.80$ [0.71;0.89] in aggregate) (Fig. 2). No statistical difference in the ratio was observed in between the younger and the older vaccinated participants.

Based on experience from studying antibody correlates of disease protection for influenza virus vaccines, a $20 \%$ reduced titer does not indicate a biologically significant change in neutralization activity $(8,9)$. The largely preserved neutralization of pseudoviruses bearing the B.1.1.7 spike by BNT162b2-immune sera makes it unlikely that the UK variant virus will escape BNT162b2-mediated protection.

A potential limitation of the work may be the use of a nonreplicating pseudovirus system. However, previous reports have shown good concordance between pseudotype neutralization and SARS-CoV-2 neutralization assays (10, 11). Still, concordance may vary looking at different SARS-CoV-2 
strains and remains to be demonstrated in case of the SARSCoV-2 B.1.1.7 lineage. Additional experiments will confirm efficient neutralization of B.1.1.7 lineage clinical isolates. This study has evaluated sera elicited by the recommended regimen of two doses administered 21 days apart and does not provide insight into neutralization if the recommended dosing regimen is not followed. The ongoing evolution of SARSCoV-2 necessitates continuous monitoring of the significance of changes for maintained protection by the currently authorized vaccines. Unlike the protocol for influenza vaccines, the degree of reduction in neutralization that might indicate a need for a strain change has not yet been established for COVID-19 vaccines. A previous study demonstrated that BNT162b2 elicits both a polyepitopic CD8+ T cell response to the encoded spike protein and virus neutralizing antibodies (7). Given the multiple potential mediators of protection elicited by BNT162b2, it is possible that vaccine efficacy could be preserved in the longer term, even with substantial losses of neutralization by vaccine-elicited sera. This view is further supported by the rapid onset of disease protection about 12 days after the first dose of BNT162b2 at a time when neutralizing antibody titers are still very low (1). Absent an established correlate of protection, clinical effectiveness data will be needed to provide definitive assessment of vaccinemediated protection against viral variants.

Although sustained neutralization of the current B.1.1.7 variant is reassuring, preparation for potential COVID-19 vaccine strain change is prudent. Adaptation of the vaccine to a new virus strain would be facilitated by the flexibility of mRNA-based vaccine technology.

\section{REFERENCES AND NOTES}

1. F. P. Polack, S. J. Thomas, N. Kitchin, J. Absalon, A. Gurtman, S. Lockhart, J. L. Perez, G. Pérez Marc, E. D. Moreira, C. Zerbini, R. Bailey, K. A. Swanson, S. Roychoudhury, K. Koury, P. Li, W. V. Kalina, D. Cooper, R. W. Frenck Jr., L. L. Hammitt, Ö. Türeci, H. Nell, A. Schaefer, S. Ünal, D. B. Tresnan, S. Mather, P. R. Dormitzer, U. Şahin, K. U. Jansen, W. C. Gruber; C4591001 Clinical Trial Group, Safety and Efficacy of the BNT162b2 mRNA Covid-19 Vaccine. N. Engl. J. Med. 383, 2603-2615 (2020). doi:10.1056/NEJMoa2034577 Medline

2. A. Rambaut, N. Loman, O. Pybus, W. Barclay, J. Barrett, A. Carabelli, T. Connor, T. Peacock, D. L. Robertson, E. Volz; COVID-19 Genomics Consortium UK (CoG-UK), Preliminary genomic characterisation of an emergent SARS-CoV-2 lineage in the UK defined by a novel set of spike mutations. virological.org (2020); https://virological.org/t/preliminary-genomic-characterisation-of-anemergent-sars-cov-2-lineage-in-the-uk-defined-by-a-novel-set-of-spikemutations $/ 563$.

3. E. Volz, S. Mishra, M. Chand, J. C. Barrett, R. Johnson, L. Geidelberg, W. R. Hinsley, D. J. Laydon, G. Dabrera, A. O'Toole, R. Amato, M. Ragonnet-Cronin, I. Harrison, B. Jackson, C. V. Ariani, O. Boyd, N. J. Loman, J. T. McCrone, S. Gonçalves, D. Jorgensen, R. Myers, V. Hill, D. K. Jackson, K. Gaythorpe, N. Groves, J. Sillitoe, D. P. Kwiatkowski, The COVID-19 Genomics UK (COG-UK) consortium, S. Flaxman, O. Ratmann, S. Bhatt, S. Hopkins, A. Gandy, A. Rambaut, N. M. Ferguson, Transmission of SARS-CoV-2 Lineage B.1.1.7 in England: Insights from linking epidemiological and genetic data. medRxiv (2021). https://doi.org/10.1101/2020.1230.20249034.
4. T. N. Starr, A. J. Greaney, S. K. Hilton, D. Ellis, K. H. D. Crawford, A. S. Dingens, M. J. Navarro, J. E. Bowen, M. A. Tortorici, A. C. Walls, N. P. King, D. Veesler, J. D. Bloom, Deep Mutational Scanning of SARS-CoV-2 Receptor Binding Domain Reveals Constraints on Folding and ACE2 Binding. Cell 182, 1295-1310.e20 (2020). doi:10.1016/i.cell.2020.08.012 Medline

5. H. Gu, Q. Chen, G. Yang, L. He, H. Fan, Y. Q. Deng, Y. Wang, Y. Teng, Z. Zhao, Y. Cui, Y. Li, X. F. Li, J. Li, N. N. Zhang, X. Yang, S. Chen, Y. Guo, G. Zhao, X. Wang, D. Y. Luo, H. Wang, X. Yang, Y. Li, G. Han, Y. He, X. Zhou, S. Geng, X. Sheng, S. Jiang, S. Sun, C. F. Qin, Y. Zhou, Adaptation of SARS-CoV-2 in BALB/c mice for testing vaccine efficacy. Science 369, 1603-1607 (2020). doi:10.1126/science.abc4730 Medline

6. X. Xie, J. Zou, C. R. Fontes-Garfias, H. Xia, K. A. Swanson, M. Cutler, D. Cooper, V. D. Menachery, S. Weaver, P. R. Dormitzer, P.-Y. Shi, Neutralization of N501Y mutant SARS-CoV-2 by BNT162b2 vaccine-elicited sera. bioRxiv (2021). https://doi.org/10.1101/2021.01.07.425740

7. U. Sahin, A. Muik, I. Vogler, E. Derhovanessian, L. M. Kranz, M. Vormehr, J. Quandt, N. Bidmon, A. Ulges, A. Baum, K. Pascal, D. Maurus, S. Brachtendorf, V. Lörks, J. Sikorski, P. Koch, R. Hilker, D. Becker, A.-K. Eller, J. Grützner, M. Tonigold, C. Boesler, C. Rosenbaum, L. Heesen, M.-C. Kühnle, A. Poran, J. Z. Dong, U. Luxemburger, A. Kemmer-Brück, D. Langer, M. Bexon, S. Bolte, T. Palanche, A. Schultz, S. Baumann, A. J. Mahiny, G. Boros, J. Reinholz, G. T. Szabó, K. Karikó, P.-Y. Shi, C. Fontes-Garfias, J. L. Perez, M. Cutler, D. Cooper, C. A. Kyratsous, P. R. Dormitzer, K. U. Jansen, Ö. Türeci, BNT162b2 induces SARS-CoV-2neutralising antibodies and $T$ cells in humans. medRxiv (2020). https://doi.org/10.1101/2020.12.09.20245175.

8. D. J. Smith, A. S. Lapedes, J. C. de Jong, T. M. Bestebroer, G. F. Rimmelzwaan, A. D. Osterhaus, R. A. Fouchier, Mapping the antigenic and genetic evolution of influenza virus. Science 305, 371-376 (2004). doi:10.1126/science.1097211 Medline

9. S. Black, U. Nicolay, T. Vesikari, M. Knuf, G. Del Giudice, G. Della Cioppa, T. Tsai, R. Clemens, R. Rappuoli, Hemagglutination inhibition antibody titers as a correlate of protection for inactivated influenza vaccines in children. Pediatr. Infect. Dis. J. 30, 1081-1085 (2011). doi:10.1097//NF.0b013e3182367662 Medline

10. J. B. Case, P. W. Rothlauf, R. E. Chen, Z. Liu, H. Zhao, A. S. Kim, L.-M. Bloyet, Q. Zeng, S. Tahan, L. Droit, M. X. G. Ilagan, M. A. Tartell, G. Amarasinghe, J. P. Henderson, S. Miersch, M. Ustav, S. Sidhu, H. W. Virgin, D. Wang, S. Ding, D. Corti, E. S. Theel, D. H. Fremont, M. S. Diamond, S. P. J. Whelan, Neutralizing Antibody and Soluble ACE2 Inhibition of a Replication-Competent VSV-SARS-CoV-2 and a Clinical Isolate of SARS-CoV-2. Cell Host Microbe 28, 475-485.e5 (2020). doi:10.1016/i.chom.2020.06.021 Medline

11. A. B. Vogel, I. Kanevsky, Y. Che, K. A. Swanson, A. Muik, M. Vormehr, L. M. Kranz, K. C. Walzer, S. Hein, A. Güler, J. Loschko, M. S. Maddur, A. Ota-Setlik, K. Tompkins, J. Cole, B. G. Lui, T. Ziegenhals, A. Plaschke, D. Eisel, S. C. Dany, S. Fesser, S. Erbar, F. Bates, D. Schneider, B. Jesionek, B. Sänger, A. K. Wallisch, Y. Feuchter, H. Junginger, S. A. Krumm, A. P. Heinen, P. Adams-Quack, J. Schlereth, S. Schille, C. Kröner, R. de la Caridad Güimil Garcia, T. Hiller, L. Fischer, R. S. Sellers, S. Choudhary, O. Gonzalez, F. Vascotto, M. R. Gutman, J. A. Fontenot, S. Hall-Ursone, K. Brasky, M. C. Griffor, S. Han, A. A. H. Su, J. A. Lees, N. L. Nedoma, E. H. Mashalidis, P. V. Sahasrabudhe, C. Y. Tan, D. Pavliakova, G. Singh, C. FontesGarfias, M. Pride, I. L. Scully, T. Ciolino, J. Obregon, M. Gazi, R. Carrion Jr., K. J. Alfson, W. V. Kalina, D. Kaushal, P.-Y. Shi, T. Klamp, C. Rosenbaum, A. N. Kuhn, Ö. Türeci, P. R. Dormitzer, K. U. Jansen, U. Sahin, BNT162b vaccines are immunogenic and protect non-human primates against SARS-CoV-2. bioRxiv (2020). https://doi.org/10.1101/2020.12.11.421008

12. M. Berger Rentsch, G. Zimmer, A vesicular stomatitis virus replicon-based bioassay for the rapid and sensitive determination of multi-species type I interferon. PLOS ONE 6, e25858 (2011). doi:10.1371/journal.pone.0025858 Medline

\section{ACKNOWLEDGMENTS}

Supported by BioNTech and Pfizer. We thank the BioNTech German clinical trial (NCT04380701, EudraCT: 2020-001038-36) participants, from whom the post-immunization human sera were obtained. We thank the many colleagues at BioNTech and Pfizer who developed and produced the BNT162b2 vaccine candidate. We thank S. Jägle and N. Beckmann for logistical support. 
Author contributions: U.S., O.T., A.M. and P.R.D. conceived and conceptualized the work. K.A.S. and A.M planned and supervised experiments. A.M., A.W., J.M., B.S., H.C, W.C. and R.S. performed experiments. A.M., D.M., H.C, and K.A.S. analyzed data. U.S., O.T., A.M., P.R.D. and K.A.S. interpreted data and wrote the manuscript. All authors supported the review of the manuscript. Competing interests:U.S. and Ö.T. are management board members and employees at BioNTech SE. A.M., A.W., J.M., B.S. and D.M. are employees at BioNTech SE. U.S., Ö.T. and A.M. are inventors on patents and patent applications related to RNA technology and COVID-19 vaccine. U.S., O.T., A.M., J.M. and B.S. have securities from BioNTech SE; K.A.S., W.C., H.C., R.S. and P.R.D. are employees at Pfizer and may have securities from Pfizer. Data and materials availability: A table of the neutralization titers is provided in table S1. Materials are available from the authors under a Materials Transfer Agreement with BioNTech. This work is licensed under a Creative Commons Attribution 4.0 International (CC BY 4.0) license, which permits unrestricted use, distribution, and reproduction in any medium, provided the original work is properly cited. To view a copy of this license, visit https://creativecommons.org/licenses/by/4.0/. This license does not apply to figures/photos/artwork or other content included in the article that is credited to a third party; obtain authorization from the rights holder before using such material.

\section{SUPPLEMENTARY MATERIALS}

science. sciencemag.org/cgi/content/full/science.abg6105/DC1

Materials and Methods

Figs. S1 to S3

Tables S1 and S2

Reference (12)

MDAR Reproducibility Checklist

16 January 2021; accepted 27 January 2021

Published online 29 January 2021

10.1126/science.abg6105 

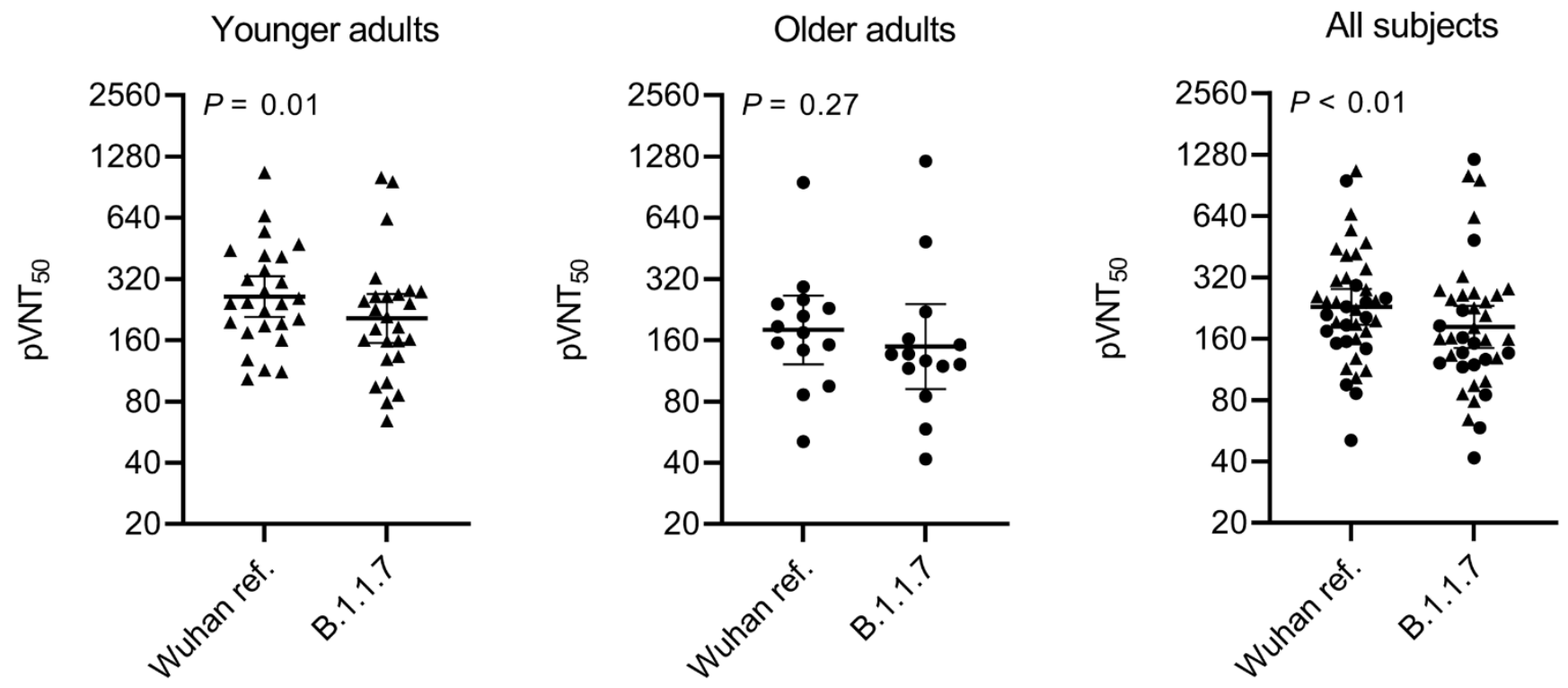

Fig. 1.50\% pseudovirus neutralization titers ( $\mathrm{pVNT}$ 50) of 40 sera from BNT162b2 vaccine recipients against VSV-SARS-CoV-2-S pseudovirus bearing the Wuhan or lineage B.1.1.7 spike protein. $N=26$ sera from younger adults (aged 23 to 55 yrs; indicated by triangles) and $n=14$ sera from older adults (aged 57 to 73 yrs; indicated by circles) drawn at either day 29 or day 43 (7 or 21 days after dose 2) were tested. Statistical significance of the difference between the neutralization of the VSV-SARS-CoV-2-S pseudovirus bearing the Wuhan or lineage B.1.1.7 spike protein was calculated by a Wilcoxon matched-pairs signed rank test. Two-tailed p-values are reported. Geometric mean titer (GMT) and 95\% confidence intervals are indicated.

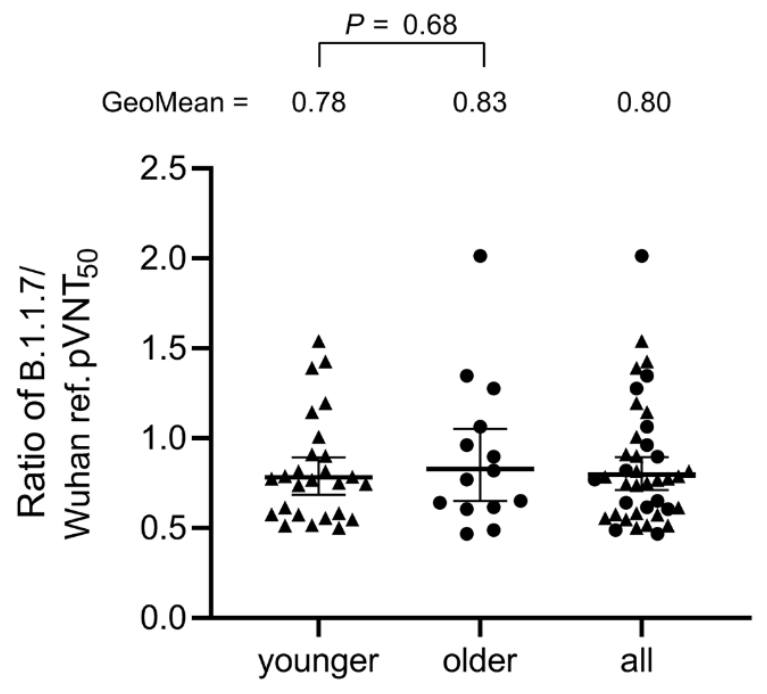

Fig. 2. Ratio of pVNT50 between SARS-CoV-2 lineage B.1.1.7 and Wuhan reference strain spike-pseudotyped VSV. Triangles represent sera from younger adults (aged 23 to $55 \mathrm{yrs}$ ), and circles represent sera from older adults (aged 56 to 73 yrs). Sera were drawn either on day 29 or day 43 (7 or 21 days after dose 2). The geometric mean ratio of pVNT 50 between SARS-CoV-2 lineage B.1.1.7 and Wuhan reference strain spike-pseudotyped VSV and 95\% confidence intervals are indicated. The difference in distribution of titer ratios between younger and older adults was tested for statistical significance with a twotailed Mann-Whitney-U test. 